\title{
Complex community responses underpin biodiversity change following invasion
}

\author{
Alessandra R. Kortz $(\mathbb{D} \cdot$ Anne E. Magurran $\mathbb{B}$
}

Received: 23 July 2020/Accepted: 1 May 2021/Published online: 7 May 2021

(C) The Author(s) 2021

\begin{abstract}
How do invasive species change native biodiversity? One reason why this long-standing question remains challenging to answer could be because the main focus of the invasion literature has been on shifts in species richness (a measure of $\alpha$ diversity). As the underlying components of community structure - intraspecific aggregation, interspecific density and the species abundance distribution (SAD) - are potentially impacted in different ways during invasion, trends in species richness provide only limited insight into the mechanisms leading to biodiversity change. In addition, these impacts can be manifested in distinct ways at different spatial scales.
\end{abstract}

Supplementary Information The online version contains supplementary material available at https://doi.org/10.1007/ s10530-021-02559-8.

A. R. Kortz ( $\square)$

Biodiversity and Natural Resources Program, Biodiversity, Ecology and Conservation Group, International Institute for Applied Systems Analysis (IIASA), Schlossplatz 1, 2361 Laxenburg, Austria e-mail: alessandrakortz@gmail.com

A. R. Kortz - A. E. Magurran

Centre for Biological Diversity, School of Biology, University of St Andrews, Fife KY16 9TH, UK

Present Address:

A. R. Kortz

Department of Invasion Ecology, Institute of Botany, Academy of Sciences of the Czech Republic, 25243 Průhonice, Czech Republic
Here we take advantage of the new Measurement of Biodiversity (MoB) framework to reanalyse data collected in an invasion front in the Brazilian Cerrado biodiversity hotspot. We show that, by using the MoB multi-scale approach, we are able to link reductions in species richness in invaded sites to restructuring in the $\mathrm{SAD}$. This restructuring takes the form of lower evenness in sites invaded by pines relative to sites without pines. Shifts in aggregation also occur. There is a clear signature of spatial scale in biodiversity change linked to the presence of an invasive species. These results demonstrate how the MoB approach can play an important role in helping invasion ecologists, field biologists and conservation managers move towards a more mechanistic approach to detecting and interpreting changes in ecological systems following invasion.

Keywords Aggregation - $\alpha$-Diversity - Density · Invasive species impact - Species abundance distributions $\cdot$ Species richness

Resumo Como espécies invasoras alteram a biodiversidade nativa? Um dos motivos pelos quais esta pergunta permanece desafiadora de ser respondida se deve ao fato de que o foco principal na literatura em invasão biológica tem sido riqueza de espécies (número de espécies-diversidade $\alpha$ ). Diferenças na riqueza de espécies podem ser causadas por alterações em um, dois ou três componentes da estrutura das 
comunidades-agregação (distribuição espacial de indivíduos intraespecíficos), densidade (abundância total de indivíduos) e na distribuição de abundância de espécies (SAD). Como cada um desses componentes são potencialmente impactados de maneira distinta pela invasão, os padrões de riqueza de espécies fornecem uma compreensão limitada sobre os mecanismos que causam alterações na biodiversidade. Esses impactos também podem ser manifestados de maneira distinta em diferentes escalas espaciais. Neste estudo nós utilizamos a recente metodologia de quantificação de biodiversidade (Measurement of Biodiversity-MoB) para reanalisar dados de invasão por pínus no hotspot de biodiversidade do Cerrado (Brasil). A metodologia MoB nos permite identificar que a redução na riqueza de espécies em áreas invadidas está especificamente associada à restruturação da $\mathrm{SAD}$ — relacionada à redução na equabilidade em áreas invadidas por pínus em relação a áreas que não contêm pínus. Também há alterações devido à agregação. A escala espacial tem um claro papel nessas alterações na biodiversidade relacionadas à invasão. Estes resultados demonstram que a metodologia MoB pode ter um papel importante para auxiliar profissionais de ecologia de invasão, biologia de campo e gestoras/es de conservação a avançar para uma abordagem mais mecanicista para detectar e interpretar as alterações na biodiversidade causadas por invasões biológicas.

\section{Introduction}

Biological invasions can lead to a range of outcomes in native ecosystems, with reported increases (e.g. Thomas and Palmer 2015), reductions (e.g. Vila et al. 2006) and no change in diversity (e.g. Meffin et al. 2010). This complexity reveals the challenge of uncovering the processes by which invasive species impact biodiversity (Courchamp et al. 2017). In this paper we draw on a new methodological approach (Measurement of Biodiversity-MoB McGlinn et al. 2019) to show how the mechanisms involved in community structuring can be disentangled to reveal how invasive taxa reshape biodiversity.

A key reason why the role of species invasions in mediating biodiversity change remains incompletely understood is because species richness (a measure of $\alpha$ diversity) is the biodiversity metric most widely used to track change in impacted systems. This is problematic because even an apparent steady state in the number of species (local species richness) in an assemblage can mask substantial shifts in a system's underlying components. For instance, untrending species richness may obscure the marked changes in species composition that invasive taxa bring about ( $\beta$ diversity, Vellend et al. 2013; Dornelas et al. 2014; Supp and Ernest 2014; Blowes et al. 2019).

However, even when shifts in species richness at a given spatial scale are reported, they are not necessarily due to a single cause, but potentially reflect change in one, two or even three underlying components of community structure-namely aggregation of individuals (how individuals within species are spatially distributed), species density (= abundance or total number of individuals) and the species abundance distribution (SAD) (Chase and Knight 2013). As such, if we are to understand the mechanisms that produce headline changes in species richness in invaded assemblages, and manage the impacts effectively, we need to be able to evaluate the role of each of these components.

Aggregation deals with the fact that the spatial distribution of individuals is rarely random. Because clusters of spatially aggregated individuals typically belong to a few species, an increase in the spatial aggregation of clusters, combined with finite assemblage capacity (Brown 1981), is likely to result in a reduction in local species richness (e.g. Chiarucci et al. 2009). Density takes account of the 'more individuals' hypothesis (Srivastava and Lawton 1998) which argues that as more individuals are encountered, species richness will increase. The $S A D$ (species abundances distribution) denotes, for a given richness and total abundance, how evenly the number of individuals is distributed amongst each species in an assemblage (evenness). It is considered one of the few "ecological laws" (e.g. McGill et al. 2007)—in natural assemblages, most species are rare and only a few common (= abundant).

PIE- the Probability of Interspecific Encounter (Hurlbert 1971), a form of Simpson's diversity index, examines the probability that two randomly selected individuals belong to different species. Since higher values of PIE are obtained from more even assemblages (Gotelli and Ellison 2013) the measure tracks change in SAD structure. As it also reflects the slope of 
the rarefaction curve at its base, PIE is relatively insensitive to sample size (Olszewski 2004; Gotelli and Ellison 2013).

Recent studies illustrate why the role of spatial scale needs to be explicitly considered in the context of biodiversity change (Primack et al. 2018; Chase et al. 2019). Patterns of change at a local scale cannot simply be extrapolated to a larger scale, as has sometimes been assumed (Chase et al. 2019). For example, studies that detect no systematic change in $\alpha$ diversity at local scales can also report biotic homogenization (e.g. Gomez et al. 2018) or differentiation (e.g. Sauer et al. 2017) at larger ones. One reason why scale is so important is because our understanding of the responses of an assemblage to an invader will depend on the spatial extent of plots, or number of individuals included in the analysis (Gotelli and Colwell 2001).

The Measurement of Biodiversity (MoB) (McGlinn et al. 2019) approach offers an exciting new opportunity to disentangle the role of these key components of assemblage structure in mediating biodiversity change following invasion. The MoB framework contains two main levels of analysis: the two-scale analysis and the multiscale analysis.

The 'two-scale' analysis examines differences in species richness at the plot level ( $\alpha$ level) and the study scale level ( $\gamma$ level) amongst treatments (e.g. invaded and uninvaded sites). As such the two-scale analysis provides an overview of richness shifts at these $\alpha$ and $\gamma$ scales, but does not treat scale as a continuum. While the two-scale analysis implies one or more of aggregation, density and the SAD in richness shifts it identifies, it is not able to pinpoint which effect(s) is (are) responsible for the detected changes (if any) (see Fig. 1 for a schematic representation of the two-scale analysis).

The multi-scale analysis complements the twoscale approach by uncovering the roles of the different components in bringing about richness change, and importantly reveals the role of spatial scaling. McGlinn et al (2019) had the critical insight that tailored comparisons of different types of accumulation and rarefaction curve constructed for the same assemblage can be used to quantify, and tease out, the influence of each of the different core components described above (namely change in intraspecific aggregation, total density and the SAD). See Fig. 2 for a schematic representation of how these curves are constructed.

The three types of curve employed by the MoB approach are: individual-based rarefaction; non-spatial, accumulation curve (= nonspatial, sample-based rarefaction curve); and plot based accumulation (= spatial, sample-based rarefaction) (Fig. 2). By contrasting pairs of curves for invaded and control treatments, the user can link differences in richness between them to the effects of the SAD, density and aggregation at the different spatial scales (visualised from left to right, or as either number of individuals or plots increases) in the study (Fig. 2). The core idea is as follows. The first curve (individual-based rarefaction) captures the structure of the SAD only as it does not contain aggregation and density effects (Hurlbert 1971; Gotelli and Colwell 2001; Cayuela et al. 2015). A comparison of individual-based rarefaction curves for treatment and control sites thus enables the user to attribute any differences between them in terms of richness to differences in SAD structure. Any differences in richness between invaded and control treatments using non-spatial sample-based rarefaction reflects the differences in species richness due to density and SAD. Finally, the plot-based accumulation curve captures information on all three effects (SAD, density and aggregation), and as such any differences in richness between the two plot-based accumulation curves (invaded and control) are due to the combination of aggregation, density and SAD effects. By drawing on the information in the pattern of mismatch in the two sets of curves (i.e. the differences between invaded and control curves in each) MoB can dissect out the effects of aggregation (b, c in Fig. 2). In the same way, comparisons of invaded and control treatments in non-spatial sample-based rarefaction and individual based rarefaction, are used to quantify the influence of density on richness differences $(a, b$ in Fig. 2). A particular advantage of the MoB approach in the context of invasion ecology is that it reveals how these different processes mediate change across the spatial scale within which the study system is placed.

We test the capacity of the MoB approach to uncover new insights into biodiversity change during invasion with a case study from the Brazilian Cerrado biodiversity hotspot. Our analysis examines two habitats in the Cerrado-campo sujo and campo úmido-occurring at the leading edge of an invasion by pine trees; this pine species (Pinus elliottii) is 


\section{Two-scale analysis}

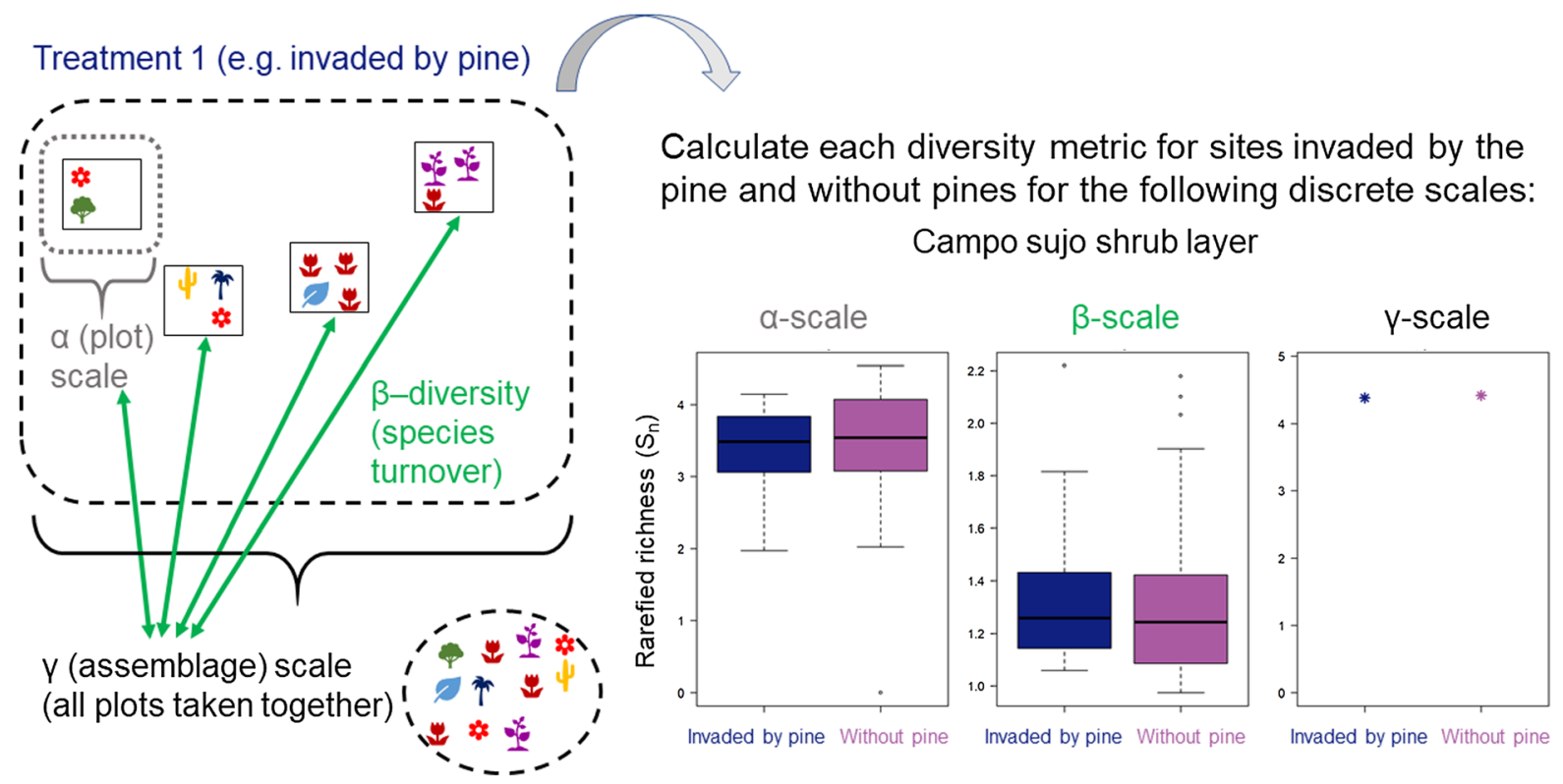

Fig. 1 Schematic representation of the two-scale analysis of the MoB package. Here spatial scale is divided into two discrete categories: $\alpha$ (plot scale) and $\gamma$-scale (assemblage scale or all plots taken together). $\beta$-scale represents the turnover (species replacement) amongst scales $(\gamma / \alpha)$. On the left hand side, black squares represent plots, and each plant shape represents one plant species. The scales considered are shown for four hypothetical plots: $\alpha$-scale, highlighted in grey for one plot, $\gamma$ scale, highlighted in black for all four plots taken together (in the bottom all species are taken together). The $\beta$-diversity component takes species composition into account by calculating which and how many species are shared between $\alpha$ and $\gamma$ scales (green arrows represent species replacement, or turnover,

considered one of the most invasive plants in the world (Richardson and Rejmánek 2011). Using the extrapolated rarefaction approach (Hsieh et al. 2016) we were previously able to show that species richness differs between invaded and control sites in the dominant vegetation layer of each habitat - the shrub layer of campo sujo and the grass layer of campo úmido (Kortz et al. 2018). A major finding was that richness decreased in the shrub layer of campo sujo habitat in invaded sites relative to the control ones (Kortz et al. 2018) but we were unable to identify the mechanisms that led to that loss of diversity. Here we use the MoB approach to ascertain how the different components of assemblage structure contributed to the observed reduction in richness in the campo sujo shrub layer, and to establish the scaling properties of these responses. We then set the results for the campo sujo amongst scales). Then, observed richness (number of species sampled), total abundance (total number of individuals or density), rarefied species richness and a conversion of the evenness metric - the effective number of species of PIE $\left(\mathrm{S}_{\mathrm{PIE}}\right)$ are calculated for each of these scales (the complete results of the two-scale analysis is reported in Table $\mathrm{S} 1$ in the Supplementary Materials). For ease of reading a hypothetical representation of plots sites invaded by pine only are shown here. The results are then plotted in boxplots showing whether a significant difference is found amongst sites invaded by pine and sites without pines. In this example no differences in rarefied richness were found between sites invaded by the pine and without pines at any scale in the shrub layer of campo sujo

shrub layer in the context of those obtained in the other parts of the system.

\section{Methods}

\section{Data collection}

We reanalysed data (Kortz et al. 2018) recorded in an invasive front of singleton invasive pine trees in the Brazilian Cerrado biodiversity hotspot. Fieldwork was carried out at the Itirapina Ecological Station, a Protected Area located in the Southeast of Brazil $\left(22^{\circ} 11^{\prime}-22^{\circ} 15^{\prime} \mathrm{S}, 47^{\circ} 51^{\prime}, 47^{\circ} 57^{\prime} \mathrm{W}\right)$. The Protected Area has been invaded by pine trees-P. elliottii Engelm. (Pinaceae) — in two key habitats, campo sujo (shrub-dominated) and campo úmido (more open, 
(a)

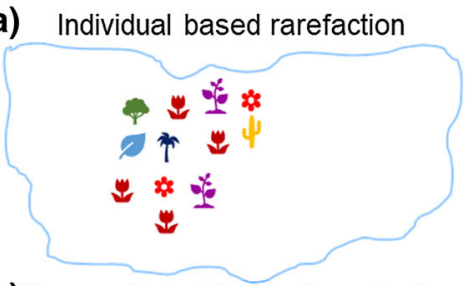

(b)Non-spatial, plot based rarefaction

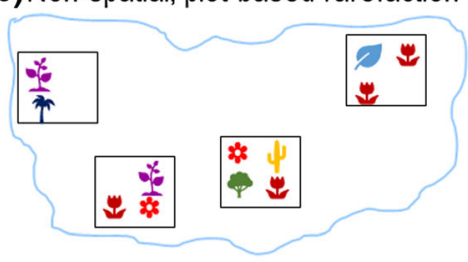

(c) Plot based accumulation

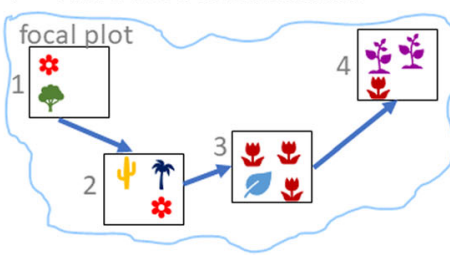

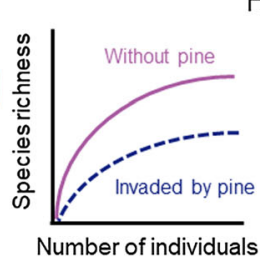
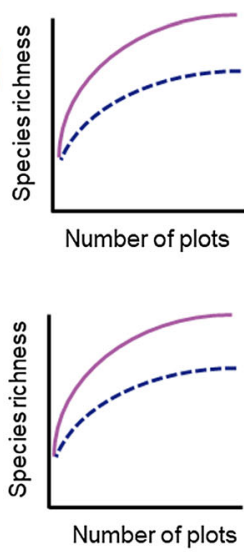

How the rarefaction curve is plotted

Differences in $\mathrm{S}$ between control and invaded are

All individuals within a due to treatment are pooled in the same "big plot" and are randomly selected to construct the curve.

.

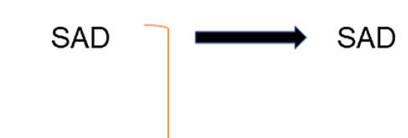

The individuals are shuffled amongst plots whilst maintaining total number of individuals per plot.

Starts with a focal plot, and then the geographically closer plots are plotted.

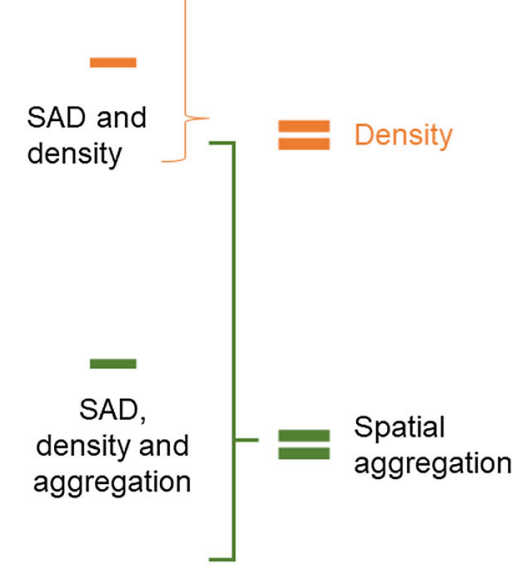

Fig. 2 Schematic representation of the three rarefaction curves deployed in the MoB framework (McGlinn et al. 2019) (multiscale analysis): a individual-based rarefaction, b nonspatial, accumulation curve (= non-spatial, sample-based rarefaction) and $\mathbf{c}$ plot based accumulation (= spatial, sample based rarefaction). Each plant symbol represents a different plant species. The three rarefaction curves treat the same dataset collected in the field (species abundance by plot) in different ways. a In the individual-based rarefaction, as in the classic individual based rarefaction (Hurlbert 1971; Gotelli and Colwell 2001), all individuals collected (in different plots) are pooled together and are then randomly selected to construct the rarefaction curve. As such, in the individual-based rarefaction curve only the SAD effect is perceived, given that there is only one "big plot" and thus the spatial aggregation and density of each real sampled plot has been broken down. b In a non-spatial, accumulation curve the global dataset is divided into plots with the same total number of individuals per plot (= total density per plot) as the original data collected in the field, but the individuals are randomly shuffled amongst plots - this removes the spatial aggregation component. Thus, in the non-spatial, accumulation curve both the effects of density and the SAD are included. $\mathbf{c}$ In the plot based accumulation (Chiarucci et al. 2009), the individuals of each species in each plot are incorporated as they were sampled in the field. This is a key difference between the classic sample-based rarefaction and the non-spatial,

grass-dominated). We sampled pairs of $5 \times 5 \mathrm{~m}$ plots containing a single pine individual (named "invaded by pine" plot) and a corresponding "without pine" plot—placed $10 \mathrm{~m}$ away at a random direction, and at least $10 \mathrm{~m}$ distant from the nearest pine tree accumulation curve, as the individuals are switched amongst plots in the latter. The calculation starts with a single focal plot that is selected first (1). The geographically closest plots are then plotted in sequence (2 to 4 ). This plot is analogous to a classic species accumulation curve (as in Gotelli and Colwell 2001); as such it incorporates spatial autocorrelation. This procedure is repeated many times and results are averaged to produce a smooth curve. Note that each of the three rarefaction curves a, $\mathbf{b}$ and $\mathbf{c}$ represent the same dataset with the same total number of species (7) and individuals (12) organized in different ways. Here spatial scale is analysed in a continuum-more plots (or individuals) represent a larger spatial scale from left to right. The difference in richness between invaded and control sites within a given plot type reflects differences that can be attributed to the mechanisms captured by that plotting method. The structured comparison of plot types, provided by MoB, makes it possible to isolate the effect of a given mechanism (the effects of the SAD are already isolated in $\mathrm{a} ; \mathrm{a}, \mathrm{b}=$ density; $\mathrm{b}, \mathrm{c}=$ spatial aggregation). There is no single recommended unit of scale (number of plots or individuals) for each of the accumulation/ rarefaction curves; in fact, they can be interchangeable without leading to differences in the curves themselves (Figures S3 and S4 in the Supplementary Materials show that the equivalent number of individuals (at the top) is equivalent to the number of plots (bottom)

individual, in both habitats. The spatial distribution of invaded and uninvaded plots is thus equivalent. In each plot we sampled plant abundance in both vegetation layers - shrub and grass layer. In the shrub layer all plant individuals were counted whereas in the 
grass layer we measured plant abundance using a point quadrat with 5 "pins" placed at 10 random direction within each plot (50 "pins" per plot in total). In total we sampled 300 plots, 114 in campo sujo (57 invaded and 57 uninvaded) and 186 in campo úmido (93 invaded and 93 uninvaded) (see (Kortz et al. 2018) for more detailed fieldwork information) (Fig. 3). The grain size of our study (plot area) is $25 \mathrm{~m}^{2}$ whereas the spatial extent (the total spatial area of the study) is $7 \mathrm{~km}^{2}$. The pine trees were not included in the calculation of the diversity metrics.

\section{Data analysis}

We used the Measurement of Biodiversity (MoB) framework (McGlinn et al. 2019) implemented in the mobr package version 2.0.2 from $\mathrm{R}$ (Mcglinn et al. 2021; R Core Team 2020).

We first computed the two-scale analysis. This analysis calculates diversity metrics in sites invaded by the pine and sites without pines considering each plot separately ( $\alpha$-scale) as well as for all plots taken together $(\gamma$-scale); $\beta$-diversity represents species turnover amongst scales $(\gamma / \alpha)$ (See Fig. 1). Detailed definitions and nomenclature of the diversity metrics used in the two-scale analysis are provided on Table S1.2 of Supplemental Materials S1 for McGlinn et al.-Measurement of Biodiversity (MoB) (https:// doi.org/10.1111/2041-210X.13102). In the two-scale analysis the nonparametric randomization test randomly shuffles plots between the treatments (e.g. areas with and without the invader), re-calculating the value of each metric in each run. It is then possible to evaluate whether there are significant differences between this null expectation and the observed values (Legendre and Legendre 2012). The two-scale analysis is calculated with the function get_mob_stats from the mobr package from R; we used 999 permutations.

Following the procedure in McGlinn et al. (2019), we next constructed the three accumulation/rarefaction curves (individual based rarefaction, the nonspatial, accumulation curve and the plot based accumulation) for each habitat and vegetation layer-see Fig. 2. We used Monte-Carlo permutation methods to build the null models used to assess the influence of each of the three processes (both the rarefaction curves and the null models are calculated with mobr get_delta_stats function). These null models are described, along with underpinning equations, in section S4 in Supplemental Materials for McGlinn
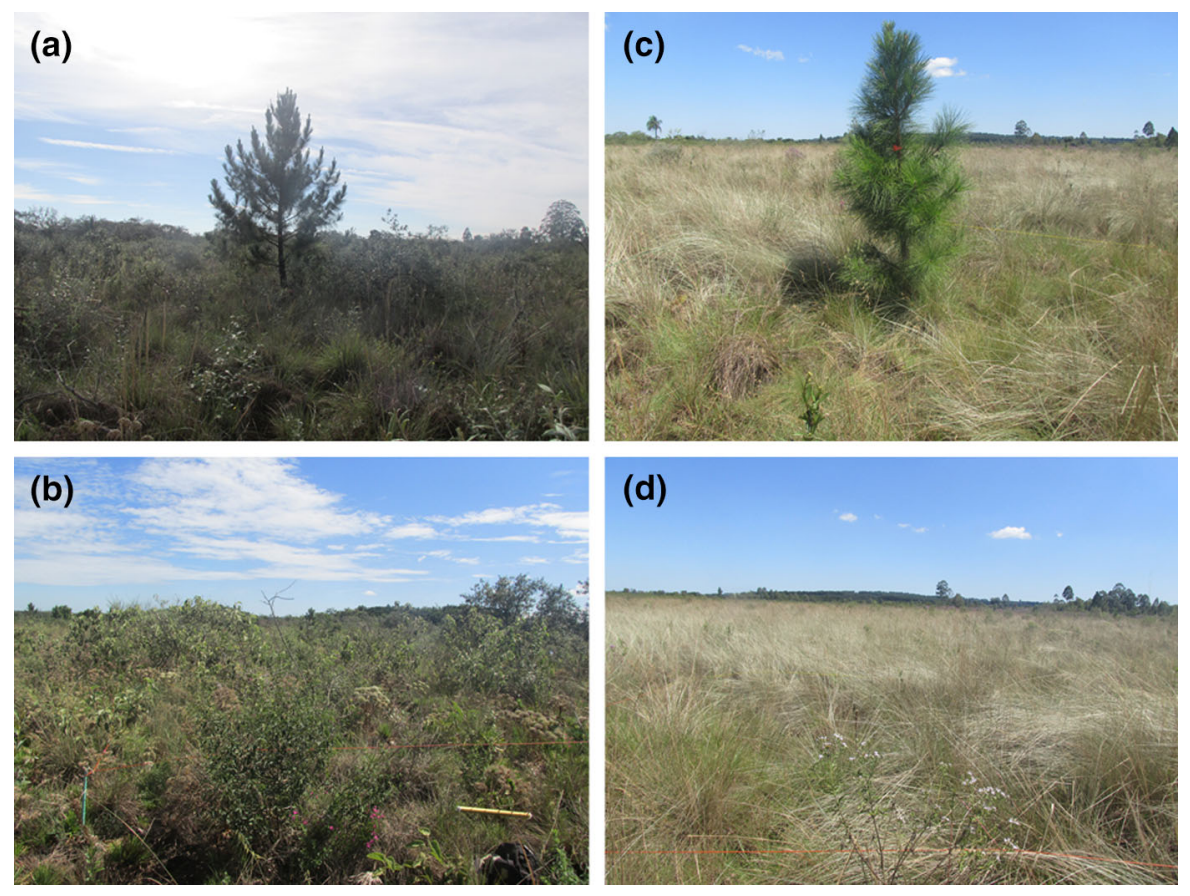

Fig. 3 Sampled habitats in the Cerrado biodiversity hotspot (Itirapina Ecological Station, Brazil): the shrub-dominated campo sujo (a and $\mathbf{b})$ and the grass-dominated campo úmido (c and $\mathbf{d}$ ) both for sites invaded by an isolated pine tree (a and $\mathbf{c})$ and control (b and $\mathbf{d})$ 
et al.-Measurement of Biodiversity (MoB) (https:// doi.org/10.1111/2041-210X.13102). In each case the null model removes treatment differences attributed to the effect of interest. The goodness-of-fit test DiggleCressie-Loosmore-Ford (DCLF) significance test was used to avoid the inflation of false positives (Loosmore and Ford 2006; Baddeley et al. 2014). The null model for spatial aggregation removes both within-plot and between-plot spatial aggregation; it compares the effect at each spatial scale against the $95 \%$ quantile of the null. The null model for density assumes a situation in which there are no treatment differences in density. The SAD null model employs a cross-treatment 'regional' SAD which it then samples. The null models generate acceptance intervals against which the observed change in richness, attributed to a given process, can be compared across scales. As McGlinn et al. (2019) note, however, these $95 \%$ zones do not support formal statistical testing but do allow an informative visualisation of where departures from the null expectation lie. All of these models are implemented in mobr package and require a large number of permutations; we used 999 permutations. We then used function plot.mob_out to plot both the rarefaction curves (display $=$ ' $\mathrm{S} \sim$ effort') and the null models for each of the components (display = 'stat $\sim$ effort').

\section{Results}

The two-scale analysis uncovered no differences in species richness in sites invaded by pines and without pines in the shrub layer of campo sujo, and for any habitat nor vegetation layer at any of the evaluated scales. The only case where the two-scale analysis did detect a difference between plots with and without pine was in the grass layer at the $\beta$-scale (Table S1).

The multiscale analysis, in contrast, reveals that in all three accumulation/rarefaction methods species richness is lower in areas invaded by the pine of the shrub layer of campo sujo, than in sites without pines in the same habitat (Fig. 4). The MoB decomposition approach (Fig. 5) allows us to examine how the different processes influence this pattern. The SAD effect is the most pronounced, since here the observed difference in richness lies outside the acceptance interval of the null model at all spatial scales, particularly at medium to large ones where the reduction approaches 20 species (Fig. 5a). This points to a reduction in evenness in invaded plots relative to control ones, an inference supported by the observation that, on average, PIE is consistently lower in invaded sites of campo sujo in the shrub layer across all spatial scales (Fig S5). Density effects, which operate in the same direction of the SAD, also contribute to the decrease in species richness in the invaded plots of the campo sujo shrub layer relative to the control ones, but only at the largest scale (Fig. 5b). Aggregation has an opposing effect as it increases richness in invaded sites, particularly at intermediate scales (Fig. 5c). This role of aggregation is manifested by the invaded and control curves being more aligned to one another when the effects of aggregation are included (Fig. 4c), compared to when the effects of aggregation are removed and invaded and control curves are further apart (the SAD Fig. 4a, and density, Fig. 4b).

The rarefaction curves of invaded and control sites of all the other treatments (the grass layer of campo sujo as well as both shrub and grass layers of campo úmido) are indistinguishable in these analyses. In each of these vegetation habitats and layers, invaded and control curves either cross or overlap (Fig S1). In addition, change in species richness attributed to each of the three components in these habitats falls mainly within the expectation of the null model (Fig S2).

MoB comparisons of species richness in invaded sites versus uninvaded sites reveal that aggregation plays a role in all four habitats, but mainly at small to intermediate spatial scales (Fig. 5, Table 1, Fig S2). In all cases, there are subtle increases in species richness in invaded sites due to a reduction in aggregation (Fig. 5c, Fig S2.c, Fig S2.f and Fig S2.i), which are only significant at small to intermediate spatial scales and converge to zero once all plots are considered, as expected for a balanced design (McGlinn et al 2019). These aggregation effects are not sufficient to lead to a shift in species richness in invaded sites compared to control in any case, apart from the campo sujo shrub layer, as noted above (Fig. 5, Fig S2). Moreover, while density depresses species richness in invaded sites of the shrub layer of campo sujo at larger spatial scales (Fig. 5) it has no influence on species richness in any of the other habitats (Fig S2). While the SAD effect is the strongest in the shrub layer of campo sujo (Fig. 5a), in that it drives the overall reduction in richness, it also leads to a subtle decrease in species 


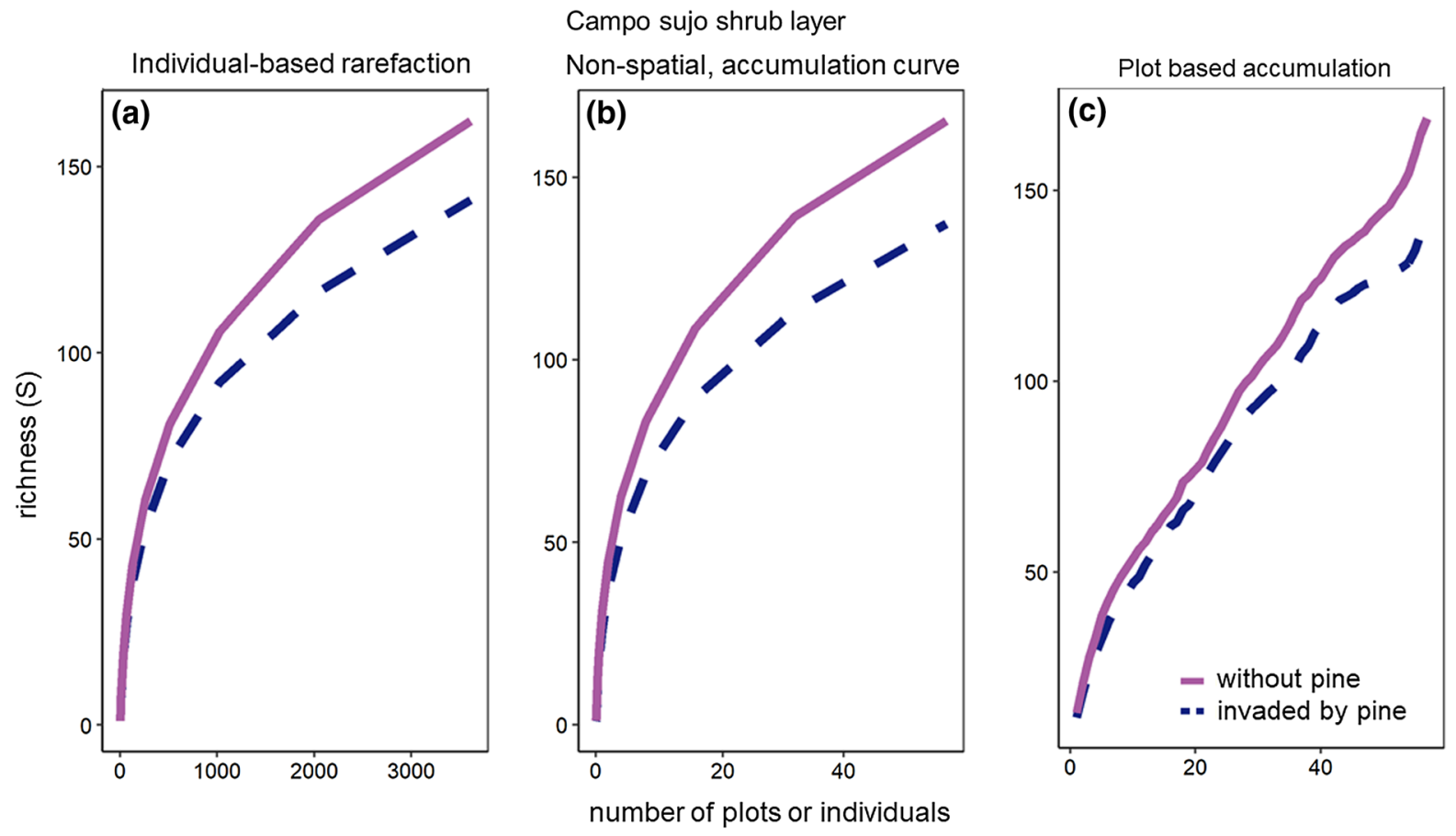

Fig. 4 Accumulation and rarefaction curves (999 permutations) for sites invaded by Pinus elliottii and those without pines in the shrub layer of campo sujo Cerrado habitat calculated using the

richness in the shrub layer of campo úmido but at very small spatial scales only (Fig S2.d, see also Figs S3 and S4 in the SM for the cumulative effects of each component).

\section{Discussion}

By applying the MoB approach to this system, we have been able to uncover substantial new insights into variation in biodiversity linked to the presence of invasive pine trees in this biodiversity hotspot. Crucially, we found that we needed the multiscale analysis to reveal the consequences for biodiversity of the invading pine trees. In particular, the multiscale analysis revealed how treating spatial scale as a continuum, rather than simply considering it at $\alpha$ and $\gamma$ levels, sheds new light on the mechanisms that lead to community restructuring following invasion.

These new insights include the key role of the SAD leading to a decrease in species richness in the shrub layer of campo sujo habitat. The density effect reinforces this outcome, but only at the largest scales, while aggregation contributes to an increase in species get_delta_stats function and plotted using plot.mob_out from the mobr package from $\mathrm{R}$ for the three curves considered

richness, but not to a sufficient degree to counteract the other components (Fig. 5). Each of these are strongly influenced by spatial scale and in different ways. The magnitude of the SAD effect increases with spatial scale. In contrast to the density effect, the aggregation effect has most influence at small to intermediate scales. In short, the SAD in particular, and density to a lesser degree, are pushing the system in one direction, aggregation effects in another (Fig. 5). Shifts in the SAD are manifested through a reduction in evenness (see Fig S5) and have the most pronounced net outcome in terms of reduction in richness. Overall, all three rarefaction curves consistently have lower species richness in sites invaded by pine than sites without pines in the shrub layer of campo sujo (Fig. 4).

Previously we reported a reduction in species richness in only one of the four habitat layers in the system i.e. the shrub layer of campo sujo. Here our MoB analysis detected the influence of each of the three components in bringing about that change. We further detected the influence of aggregation, but this was evident only at small scales in all cases apart from the campo sujo shrub layer. Interestingly we noted a $\mathrm{SAD}$ effect in the campo úmido shrub layer as well as 
Campo sujo shrub layer

SAD

(a)

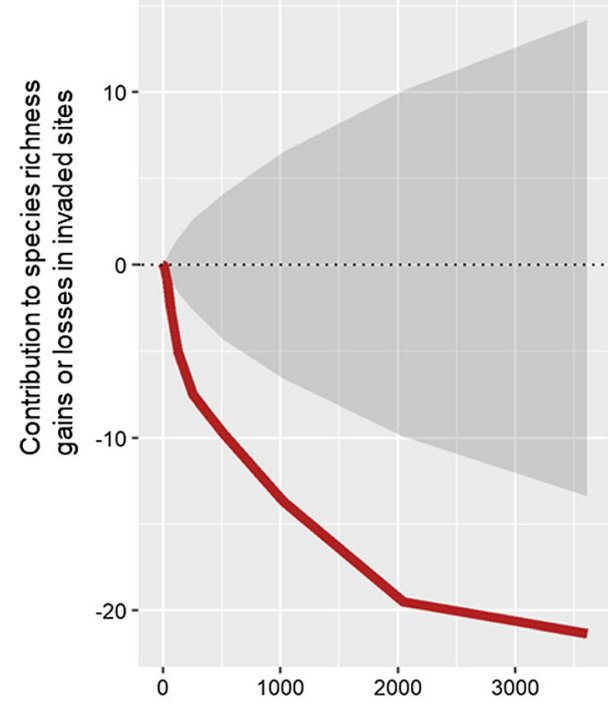

density

(b)

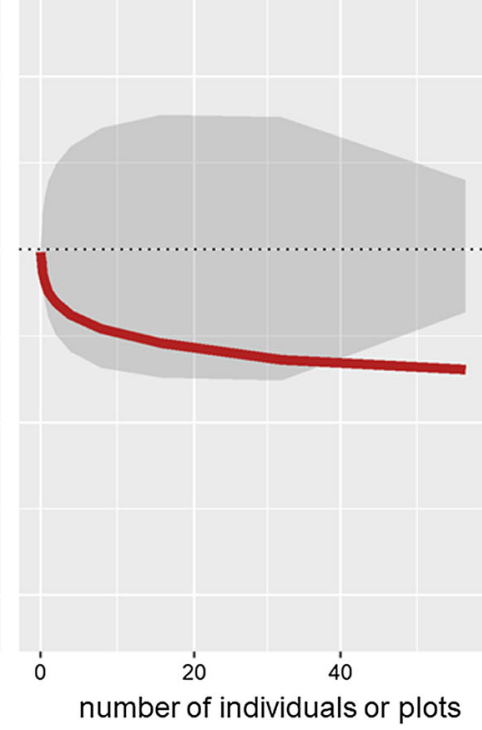

aggregation

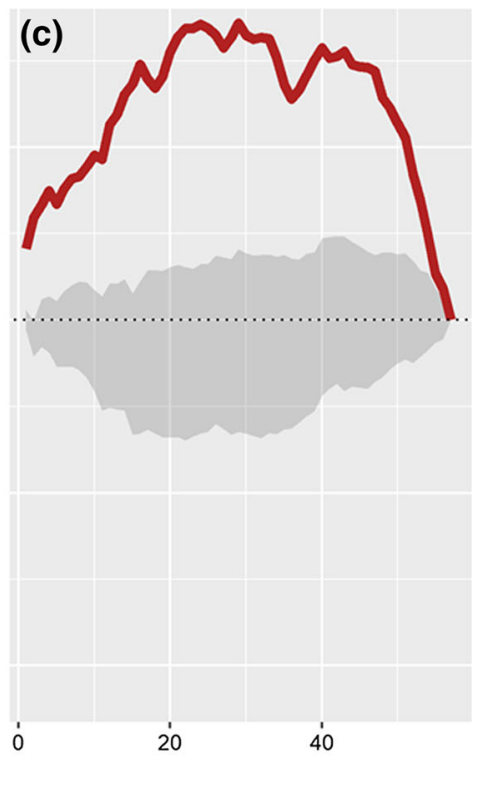

Fig. 5 Effect of invasion on richness as a function of scale for the three components. Contribution to gains (above the dotted line) and losses (below the dotted line) in species richness in sites invaded by pine compared to sites without pines in relation to $95 \%$ quantile of the null model expectation (in dark grey) due

in the the campo sujo shrub layer, but in the former case this was present at small spatial scales and insufficient to leverage an overall change in richness. Our earlier work (Kortz et al. 2018) reported an increase in richness in the campo úmido grass layer, i.e. the dominant vegetation layer in that habitat. This effect was not discernible in the MoB analysis, however. One reason could be due to the fact the $\mathrm{MoB}$ analysis requires abundance data, whereas the previous analyses used a different dataset of incidence data (Kortz et al. 2018) (see also Fig S6).

In our earlier analysis we hypothesised that observed shifts in species richness in the dominant vegetation layer were associated with changes in species relative abundances (Kortz et al. 2018). The method (Cayuela et al. 2015) we used then employs a randomization algorithm to construct the null distribution and compare the two rarefaction curves. It pointed towards changes in the relative abundance of species and species composition being responsible for the change in richness identified in that work, without allowing us tease out the roles of the different to the SAD (a), density (b) and aggregation (c) for the shrub layer of campo sujo Cerrado habitat calculated using plot.mob_out function from the mobr package from R. An increase in spatial scale is seen from left to right, reflecting the increase in the number of plots/individuals in each case

components of biodiversity change. Now we have been able to increase our understanding of how the singleton invasive pine trees are restructuring the invaded sites both by fostering spatial rearrangements in native plant individuals, and through reductions in evenness linked to the SAD effect. This conclusion would not be possible with classical biodiversity metrics.

The results obtained here using the MoB approach suggest that both inter- and intra-specific competition may be involved in restructuring the system during invasion. Our results suggest that changes in the relative abundance of native species could contribute to biodiversity change following invasions. For example, because PIE, a measure of eveness, is sensitive to changes in the dominant species (Chase et al. 2018), our finding of a consistent reduction in PIE in invaded sites across spatial scales (Fig S5) is in line with the inference that invasive pine trees are contributing to shifts in relative abundances in favour of dominant taxa. In addition, trees are not a dominant lifeform in these Cerrado habitats, and as such the pine trees 
Table 1 Summary of the MoB multi-scale analysis results for the four habitat layers (Fig. 4 and I Fig S1)

\begin{tabular}{|c|c|c|c|c|}
\hline Metric & $\begin{array}{l}\text { Campo sujo } \\
\text { Shrub layer }\end{array}$ & $\begin{array}{l}\text { Campo sujo } \\
\text { Grass layer }\end{array}$ & $\begin{array}{l}\text { Campo úmido } \\
\text { Shrub layer }\end{array}$ & $\begin{array}{l}\text { Campo úmido } \\
\text { Grass layer }\end{array}$ \\
\hline \multicolumn{5}{|c|}{ A. Accumulation/rarefaction curve } \\
\hline $\begin{array}{l}\text { Individual based } \\
\text { rarefaction }\end{array}$ & Invaded $<$ without pines & Undistinguishable & Undistinguishable & Undistinguishable \\
\hline $\begin{array}{l}\text { Non-spatial, } \\
\text { accumulation } \\
\text { curve }\end{array}$ & Invaded $<$ without pines & Undistinguishable & Undistinguishable & Undistinguishable \\
\hline $\begin{array}{l}\text { Plot based } \\
\text { accumulation }\end{array}$ & Invaded $<$ without pines & Undistinguishable & Undistinguishable & Undistinguishable \\
\hline \multicolumn{5}{|c|}{ B. $\Delta \mathrm{S}$ between invaded sites and sites without pines } \\
\hline $\begin{array}{l}\Delta \mathrm{S} \text { due to the } \\
\text { SAD }\end{array}$ & $\begin{array}{l}\text { Invaded }<\text { without pines: effect } \\
\text { magnitude increases with spatial } \\
\text { scale }\end{array}$ & No change & $\begin{array}{l}\text { Invaded }<\text { without } \\
\text { pines at small spatial } \\
\text { scales }\end{array}$ & No change \\
\hline $\begin{array}{l}\Delta \mathrm{S} \text { due to } \\
\text { density }\end{array}$ & $\begin{array}{l}\text { Invaded }<\text { without pines at the } \\
\text { largest spatial scale }\end{array}$ & No change & No change & No change \\
\hline $\begin{array}{l}\Delta \mathrm{S} \text { due to } \\
\text { aggregation }\end{array}$ & $\begin{array}{l}\text { Invaded }>\text { without pines at small } \\
\text { to intermediate spatial scales }\end{array}$ & $\begin{array}{l}\text { Invaded }>\text { without } \\
\text { pines at small spatial } \\
\text { scales }\end{array}$ & $\begin{array}{l}\text { Invaded }>\text { without } \\
\text { pines at small spatial } \\
\text { scales }\end{array}$ & $\begin{array}{l}\text { Invaded }>\text { without } \\
\text { pines at small spatial } \\
\text { scales }\end{array}$ \\
\hline
\end{tabular}

Interpretation of this analysis requires: A. comparison of sites invaded by pine and without pines for the three sets of rarefaction curves to check if they are different (Fig. 4, Fig S1), and do not cross one another, and B. evaluating the effect of each of the three components (the SAD, density and aggregation) in relation to the null expectation across scale (Fig. 5, Fig S2). In the shrub layer of campo sujo habitat species richness in invaded sites is consistently lower than sites without pines in all three rarefaction curves. This is explained by a decrease in species richness in invaded sites in relation to sites without pines due to the SAD- the magnitude of the effect increases with spatial scale. For all other conditions, rarefaction curves of sites with and without pines are undistinguishable (Fig S1), and increases in species richness in invaded sites due to aggregation are only perceived at small spatial scales (all cases) (Fig S2)

themselves contribute to altering vegetation structure and causing more shade as they grow. The pines may be also leading to changes in the mycorrhiza in the soil (Dickie et al. 2010). It is thus possible that invasive species mediated change in the relative abundance of species is a widespread-but as yet little exploredphenomenon, particularly at the earliest stages of invasion. As ours is an observational study, additional experimental studies are necessary to test these ideas and we cannot rule out the explanation that pre existing characteristics of invaded sites may have favoured pine invasion. However, we note that the sampling plot design we employed $(5 \times 5 \mathrm{~m})$ was sufficient to make robust estimates of plant diversity (Kortz et al. 2018), and the paired design enabled examination of changes in this diversity associated with pine presence.
The role of spatial scale in biodiversity change in the context of invasions

It is already clear that patterns of change in species richness are scale-dependent, and that the nature of these changes can vary across systems (Chase and Knight 2013; Chase et al. 2018, 2019). However, while invaded systems also exhibit a range of scaling responses (Levine et al. 2003; Vilà et al. 2011) few studies explicitly include different spatial scales (e.g. Meffin et al. 2010). This makes it difficult to infer general patterns. A negative relationship between invasion and diversity has been proposed at small spatial scales, whereas there is evidence for a positive relationship at the larger, regional scale (Stohlgren et al. 1999; Levine and D'Antonio 1999; Levine 2000; Powell et al. 2011, 2013). Competition is also considered more important at small spatial scales (Park et al. 2020) with environment filtering playing a greater role as scale increased. 
A recent systematic review and global metanalysis (Peng et al. 2019, based on 204 individual studies from 101 publications) found that the native-exotic species richness relationship is indeed strongly scale dependent, but the authors did not find consistently negative relationships at small spatial scales, nor were these patterns consistently positive at larger spatial scales. It is also crucial to specify the actual scale considered. Both in Peng et al. (2019) and Park et al. (2020), small spatial scale is referred as the plot or assemblage scale, whereas large scale refers to regional or country level. Fridley et al. (2004), on the other hand, evaluated the relationship between native and exotic species richness at four discrete spatial scales $(0.01,0.1,1$ and $100 \mathrm{~m}^{2}$ ) —all of which would be equivalent to the plot or assemblage (thus "small") spatial scale in Peng et al. (2019) and Park et al. (2020). The relationships between native-exotic species richness found by Fridley et al. (2004) are not consistent either when all viewed as small scale. A particular advantage of the MoB framework is that it provides a way to explicitly consider the scale effect from very fine levels to much larger ones, and in doing so can help resolve this longstanding debate. It is also worth emphasizing the distinction between comparing overall patterns of invasive species richness and native species richness from the impacts of invasive species on native assemblages - the MoB approach specifically allows the user to examine the latter. We found no support (in neither the habitat nor vegetation layer) for the assertion that the effects of invasion are consistently negative at small spatial scales and positive at larger scales (in line with Peng et al. 2019), but instead concluded that the effect of each component is either positive (aggregation) or negative (density and SAD) and strongly affected by spatial scale: at small and intermediate scales for aggregation, at larger scales for density and that the magnitude of the effect increases with spatial scale for the SAD (Table 1).

Focusing on the SAD will help elucidating invasion impacts

The SAD is an intuitive visualization of the structure of a community and it is regarded as a powerful tool in conservation and management (McGill et al. 2007). However, the role of biological invasions in bringing about change in the shape of the SAD is still, quite surprisingly, poorly understood. Better understanding of this is needed to uncover the mechanisms leading to biodiversity change and ultimately to enhance management strategies (Matthews and Whittaker 2015). Another aspect further complicating the understanding of biodiversity change following invasions is that invasive species impacts are often context-dependent. As we show here, the same invasive species can be associated with a reduction in species richness $\mathrm{v}$. no changes in species richness between sites invaded by pine and without pines, depending on the habitat and vegetation layer. As noted above, our results are based on an observational sampling study. Follow-on experimental studies would allow us to better understand the dynamics of the invasive species in both habitats and layers, but are not possible in this protected area, in which manipulations are prohibited and, in any case, unethical. Given these restrictions, which will also apply in other protected areas, the MoB framework has an important role as a tool to be used to better understand the context dependence of responses to invasions.

In the light of our findings we expect that invasions over short time scales are more likely to lead to change in the relative abundance of species than extinctions (e.g. Davis 2003). Theory (Catford et al. 2018) predicts that gradual changes in relative abundance of species precede species extinctions; this is supported by empirical evidence (e.g. Bellard et al. 2016). Change in relative abundances brought about by the presence of invasive species is explicitly quantified in relation to the SAD effect in the MoB framework. This powerful approach brings a novel opportunity to conduct an integrated analysis of the roles of the SAD and scale in invasion ecology and has the capacity to transform how we interpret, identify, and manage invasions impacts.

The MoB framework requires abundance data for different treatments (e.g. with and without the invader) sampled from an equivalent grain size. As long as these data are available it can be applied to systems of any organism-from fish to tropical plants. It does however involve pairwise comparisons as these are needed to identify the contrasts within and between the different types of rarefaction curve. By identifying the mechanisms underpinning biodiversity change during invasion, MoB will help ecologists, managers and invasion specialists to shed light to the consequences of invasions for biodiversity. As we have shown here, $\mathrm{MoB}$ can detect the impacts of invasive species, even 
at the earliest stages of invasion-something that is vital for the management of invaded systems (Simberloff et al. 2013).

Acknowledgements We thank the Forestry Institute in Brazil, Denise Zanchetta and Helena D. Lutgens for permission to conduct fieldwork in the area (permission number 479/2014 D074/2014 BA); Eric Y. Kataoka, Ana Carolina D. Castello and Rafael O. Xavier for valuable help with species identification; Luis A. Joaquim for fieldwork assistance; and the Programa de Pós Graduação em Ecologia e Recursos Naturais from the Universidade Federal de São Carlos for logistic support. ARK thanks Ciência sem Fronteiras/Coordenação de Aperfeiçoamento de Pessoal de Nível Superior (CAPES) for a fully funded $\mathrm{PhD}$ fellowship at the University of St Andrews (1091/13-1) and the School of Biology of the University of St Andrews. ARK acknowledges a Postdoctoral fellowship at the International Institute for Applied Systems Analysis (IIASA) funded by CAPES (88881.308367/2018-01) and AEM thanks the Leverhulme Trust (RPG-2019-402) for support. We thank Faye Moyes for assistance with editing the plots as well as the editor and both anonymous reviewers for insightful comments that have improved our manuscript. We also thank Dan McGlinn for the fruitful discussion and advice on plotting the MoB accumulation/rarefaction curves.

Authors' contributions Both authors contributed to the study conception and design. Material preparation, data collection and analysis were performed by Alessandra R. Kortz, data interpretation was conducted by both Alessandra R. Kortz and Anne E. Magurran. The first draft of the manuscript was written by Alessandra R. Kortz and both authors wrote and edited subsequent versions of the manuscript. Both authors read and approved the final manuscript.

Funding Open access funding provided by International Institute for Applied Systems Analysis (IIASA). This work was funded by Ciência sem Fronteiras/Coordenação de Aperfeiçoamento de Pessoal de Nível Superior (CAPES) (1091/13-1), CAPES (88881.308367/2018-01) to ARK and by the Leverhulme Trust (RPG-2019-402) to AEM.

Availability of data and materials The research data supporting this publication can be accessed at https://doi.org/ 10.17630/7ce35a28-7d44-4803-a86a-ed2b79da4ecf.

Code availability Code is available in the cited publication.

\section{Declarations}

Conflict of interest The authors declare that they have no conflict of interest.

Ethical approval Approval to conduct fieldwork at the Itirapina Ecological Station was obtained within the Forestry Institute in Brazil (permission number 479/2014 D074/2014 BA).
Open Access This article is licensed under a Creative Commons Attribution 4.0 International License, which permits use, sharing, adaptation, distribution and reproduction in any medium or format, as long as you give appropriate credit to the original author(s) and the source, provide a link to the Creative Commons licence, and indicate if changes were made. The images or other third party material in this article are included in the article's Creative Commons licence, unless indicated otherwise in a credit line to the material. If material is not included in the article's Creative Commons licence and your intended use is not permitted by statutory regulation or exceeds the permitted use, you will need to obtain permission directly from the copyright holder. To view a copy of this licence, visit http://creativecommons.org/licenses/by/4.0/.

\section{References}

Baddeley A, Diggle PJ, Hardegen A et al (2014) On tests of spatial pattern based on simulation envelopes. Ecol Monogr 84:477-489. https://doi.org/10.1890/13-2042.1

Bellard C, Cassey P, Blackburn TM (2016) Alien species as a driver of recent extinctions. Biol Lett 12:20150623. https:// doi.org/10.1098/rsbl.2015.0623

Blowes SA, Supp SR, Antão LH et al (2019) The geography of biodiversity change in marine and terrestrial assemblages. Science (80-) 366:339-345. https://doi.org/10.1126/ science.aaw 1620

Brown JH (1981) Two decades of homage to Santa Rosalia: toward a general theory of diversity. Am Zool 21:877-888

Catford JA, Bode M, Tilman D (2018) Introduced species that overcome life history tradeoffs can cause native extinctions. Nat Commun 9:2131. https://doi.org/10.1038/ s41467-018-04491-3

Cayuela L, Gotelli NJ, Colwell RK (2015) Ecological and biogeographic null hypotheses for comparing rarefaction curves. Ecol Monogr 85:437-455. https://doi.org/10.1890/ 14-1261.1

Chase JM, Knight TM (2013) Scale-dependent effect sizes of ecological drivers on biodiversity: why standardised sampling is not enough. Ecol Lett 16:17-26. https://doi.org/10. 1111/ele. 12112

Chase JM, McGill BJ, McGlinn DJ et al (2018) Embracing scale-dependence to achieve a deeper understanding of biodiversity and its change across communities. Ecol Lett 21:1737-1751. https://doi.org/10.1111/ele.13151

Chase JM, McGill BJ, Thompson PL et al (2019) Species richness change across spatial scales. Oikos 128:1079-1091. https://doi.org/10.1111/oik.05968

Chiarucci A, Bacaro G, Rocchini D et al (2009) Spatially constrained rarefaction: incorporating the autocorrelated structure of biological communities into sample-based rarefaction. Community Ecol 10:209-214. https://doi.org/ 10.1556/ComEc.10.2009.2.11

Courchamp F, Fournier A, Bellard C et al (2017) Invasion biology: specific problems and possible solutions. Trends Ecol Evol 32:13-22. https://doi.org/10.1016/j.tree.2016. 11.001 
Davis. Ma (2003) Biotic globalization: does competition from introduced species threaten biodiversity? Bioscience 53:481. https://doi.org/10.1641/00063568(2003)053[0481:BGDCFI]2.0.CO;2

Dickie IA, Bolstridge N, Cooper JA, Peltzer DA (2010) Coinvasion by Pinus and its mychorrhizal fungi. New Phytol 187:475-484

Dornelas M, Gotelli NJ, McGill B et al (2014) Assemblage time series reveal biodiversity change but not systematic loss. Science (80-) 344:296-299. https://doi.org/10.1126/ science. 1248484

Fridley JD, Brown RL, Bruno JF (2004) Null models of exotic invasion and scale-dependent patterns of native and exotic species richness. Ecology 85:3215-3222. https://doi.org/ 10.1890/03-0676

Gomez CG, Gonzalez A, Guzman HM (2018) Multiscale change in reef coral species diversity and composition in the Tropical Eastern Pacific. Coral Reefs 37:105-120. https://doi.org/10.1007/s00338-017-1637-y

Gotelli NJ, Colwell RK (2001) Quantifying biodiversity: procedures and pitfalls in the measurement and comparison of species richness. Ecol Lett 4:379-391. https://doi.org/10. 1046/j.1461-0248.2001.00230.x

Gotelli NJ, Ellison AM (2013) The measurement of biodiversity. In: A primer of ecological statistics, 2nd edn. Sinauer associates, Massachusetts, pp 449-82

Hsieh TC, Ma KH, Chao A (2016) iNEXT: An R package for rarefaction and extrapolation of species diversity (Hill numbers). Methods Ecol Evol. https://doi.org/10.1111/ 2041-210X.12613

Hurlbert SH (1971) The nonconcept of species diversity: a critique and alternative parameters. Ecology 52:577-585. https://doi.org/10.2307/1934145

Kortz AR, Silva Matos DM, Magurran AE (2018) From individuals to communities: how singleton invasive pine saplings lead to biodiversity change in the Brazilian Cerrado hotspot. J Veg Sci 29:824-834. https://doi.org/10.1111/jvs. 12668

Legendre P, Legendre L (2012) Matrix algebra. In: Legendre P, Legendre L (eds) Developments in environmental modelling. Elsevier, Amsterdam, pp 59-107

Levine JM (2000) Species diversity and biological invasions: relating local process to community pattern. Science (80-) 288:852-854. https://doi.org/10.1126/science.288.5467. 852

Levine JM, D'Antonio CM (1999) Elton revisited: a review of evidence linking diversity and invasibility. Oikos 87:15. https://doi.org/10.2307/3546992

Levine JM, Vilà M, D'Antonio CM et al (2003) Mechanisms underlying the impacts of exotic plant invasions. Proc R Soc B Biol Sci 270:775-781. https://doi.org/10.1098/rspb. 2003.2327

Loosmore NB, Ford ED (2006) Statistical inference using the $g$ or k point pattern spatial statistics. Ecology 87:1925-1931. https://doi.org/10.1890/0012-9658(2006)87[1925: SIUTGO]2.0.CO;2

Matthews TJ, Whittaker RJ (2015) REVIEW: On the species abundance distribution in applied ecology and biodiversity management. J Appl Ecol 52:443-454. https://doi.org/10. $1111 / 1365-2664.12380$
McGill BJ, Etienne RS, Gray JS et al (2007) Species abundance distributions: moving beyond single prediction theories to integration within an ecological framework. Ecol Lett 10:995-1015. https://doi.org/10.1111/j.1461-0248.2007. 01094.x

McGlinn DJ, Xiao X, May F et al (2019) Measurement of Biodiversity (MoB): A method to separate the scale-dependent effects of species abundance distribution, density, and aggregation on diversity change. Methods Ecol Evol 10:258-269. https://doi.org/10.1111/2041-210X.13102

Mcglinn DJ, Xiao X, Mcgill BJ et al (2021) mobr: Measurement of Biodiversity. $\mathrm{R}$ package version 2.0.2

Meffin R, Miller AL, Hulme PE, Duncan RP (2010) BIODIVERSITY RESEARCH: Experimental introduction of the alien plant Hieracium lepidulum reveals no significant impact on montane plant communities in New Zealand. Divers Distrib 16:804-815. https://doi.org/10.1111/j.14724642.2010.00684.x

Olszewski T (2004) A unified mathematical framework for the measurement of richness and evenness within and among multiple communities. Oikos 104:377-387. https://doi.org/ 10.1111/j.0030-1299.2005.13000.x

Park DS, Feng X, Maitner BS et al (2020) Darwin's naturalization conundrum can be explained by spatial scale. Proc Natl Acad Sci 117:10904-10910. https://doi.org/10.1073/ pnas. 1918100117

Peng S, Kinlock NL, Gurevitch J, Peng S (2019) Correlation of native and exotic species richness: a global meta-analysis finds no invasion paradox across scales. Ecology 100:1-10. https://doi.org/10.1002/ecy.2552

Powell KI, Chase JM, Knight TM (2011) A synthesis of plant invasion effect on biodiversity across spatial scales. Am J Bot 98:539-548. https://doi.org/10.3732/ajb.1000402

Powell KI, Chase JM, Knight TM (2013) Invasive plants have scale-dependent effects on diversity by altering speciesarea relationships. Science (80-) 339:316-318. https://doi. org/10.1126/science. 1226817

Primack RB, Miller-Rushing AJ, Corlett RT et al (2018) Biodiversity gains? The debate on changes in local- vs globalscale species richness. Biol Conserv 219:A1-A3. https:// doi.org/10.1016/j.biocon.2017.12.023

R Core Team (2020) R: A language and environment for statistical computing. R Core Team, Vienna

Richardson DM, Rejmánek M (2011) Trees and shrubs as invasive alien species-a global review. Divers Distrib 17:788-809. https://doi.org/10.1111/j.1472-4642.2011. 00782.x

Sauer JR, Pardieck KL, Ziolkowski DJ et al (2017) The first 50 years of the North American Breeding Bird Survey. Condor 119:576-593. https://doi.org/10.1650/CONDOR-1783.1

Simberloff D, Martin J-L, Genovesi P et al (2013) Impacts of biological invasions: what's what and the way forward. Trends Ecol Evol 28:58-66. https://doi.org/10.1016/j.tree. 2012.07.013

Srivastava DS, Lawton JH (1998) Why more productive sites have more species: an experimental test of theory using tree-hole communities. Am Nat 152:510-529. https://doi. org/10.1086/286187

Stohlgren TJ, Binkley D, Chong GW et al (1999) Exotic plant species invade hot spots of native plant diversity. Ecol 
Monogr 69:25-46. https://doi.org/10.1890/00129615(1999)069[0025:EPSIHS]2.0.CO;2

Supp SR, Ernest SKM (2014) Species-level and communitylevel responses to disturbance: a cross-community analysis. Ecology 95:1717-1723. https://doi.org/10.1890/132250.1

Thomas CD, Palmer G (2015) Non-native plants add to the British flora without negative consequences for native diversity. Proc Natl Acad Sci 112:4387-4392. https://doi. org/10.1073/pnas.1423995112

Vellend M, Baeten L, Myers-Smith IH et al (2013) Global metaanalysis reveals no net change in local-scale plant biodiversity over time. Proc Natl Acad Sci 110:19456-19459. https://doi.org/10.1073/pnas.1312779110
Vila M, Tessier M, Suehs CM et al (2006) Local and regional assessments of the impacts of plant invaders on vegetation structure and soil properties of Mediterranean islands. J Biogeogr 33:853-861. https://doi.org/10.1111/j.13652699.2005.01430.x

Vilà M, Espinar JL, Hejda M et al (2011) Ecological impacts of invasive alien plants: a meta-analysis of their effects on species, communities and ecosystems. Ecol Lett 14:702-708. https://doi.org/10.1111/j.1461-0248.2011. 01628.x

Publisher's Note Springer Nature remains neutral with regard to jurisdictional claims in published maps and institutional affiliations. 